\title{
EML4/ALK Fusion Gene Variant 5a
}

National Cancer Institute

\section{Source}

National Cancer Institute. EML4/ALK Fusion Gene Variant 5a. NCI Thesaurus. Code C99731.

A fusion gene $(\sim 2.0 \mathrm{~kb})$ that results from a chromosomal inversion inv(2)(p21p23) which fuses exon 2 of the EML4 gene with exons 20-29 of the ALK gene. This fusion is associated with non-small cell lung cancer. 